\title{
Zuverlässiges Adhäsiv dank hoher Techniktoleranz
}

Der klinische Erfolg eines Adhäsivs hängt oft von der Technik des Anwenders ab. Total-Etch-Adhäsive erfordern in der Regel ein „Wet Bonding“: Das Adhäsiv sollte dabei auf eine leicht feuchte, geätzte Dentinoberfläche aufgetragen werden. Das verhindert Übertrocknung. Aber wie feucht darf eine Oberfläche sein, um mit einem Adhäsiv noch gute Scherhaftwerte zu erzielen? Adhese Universal funktioniert sowohl auf trockenem, als auch auf feuchtem Dentin. Es vereint hydrophile und hydrophobe Eigenschaften in einem Produkt. Es ist tolerant gegenüber Feuchtigkeit und dringt gut in offene Dentintubuli ein. Die Einwirkzeit ist so gewählt, dass durch hydrophile Monomere und Wasser ein „Rewetting“ erfolgt und das Adhäsiv in das Kollagengeflecht diffundieren kann. Beim Verblasen des Adhäsivs entsteht auch bei

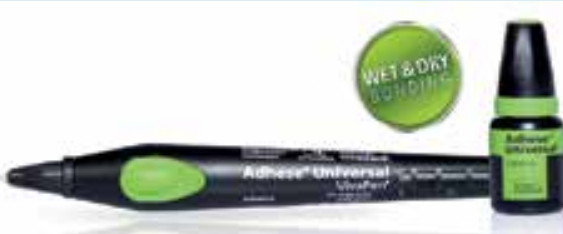

starkem Luftstrom eine gleichmässige, homogene Schicht. Ausgehärtet sorgt sie für eine optimale Versiegelung des Dentins.

Selbst nach vorheriger Phosphorsäureätzung oder bei Überfeuchtung bzw. Übertrocknung der Dentinoberfläche wird der Dentinverbund nicht beeinträchtigt Eine aktuelle Studie (Singhai et al., University at Buffalo, USA 2014) belegt dies.

Nach einer Pressemitteilung der Ivoclar Vivadent GmbH, Ellwangen (Jagst)

Internet: www.ivoclarvivadent.de 